\title{
Zasady przeciw immersji. Zaangażowanie w narrację i zaangażowanie w system formalny gry
}

Zasady gier i fabułę od lat wiąże burzliwa relacja. Na gruncie game studies ten konflikt objawił się pod wieloma postaciami, najgłośniej przy okazji sporu ludologów z narratologami. W grach, które łączą przyjemności związane ze śledzeniem narracji i te wywołane przez pokonywanie kolejnych, coraz trudniejszych wyzwań, często mówi się o dysonansie ludo-narracyjnym. Niektórzy gracze zakładają nawet jakoby mechanika i fabuła były sobie przeciwstawne, a zaangażowanie w system mechaniczny i immersja nie mogły występować $\mathrm{w}$ tej samej grze. $\mathrm{W}$ poniższym tekście postaram się zmierzyć $\mathrm{z}$ tą opinią.

\section{Problem badawczy}

Artykuł ten prezentuje zagadnienie dwóch typów zaangażowania w grę: system zasad lub narrację, w szczególności będzie mnie interesować sposób projektowania mechanik gry wyraźnie preferujący jedną z dwóch przyjemności. Problem opisuję na podstawie analizy Angry Birds [Rovio Entertainment 2009] - casualowej gry zręcznościowo-logicznej, która angażuje odbiorcę przede wszystkim mechaniką rozgrywki oraz The Walking Dead [Telltale Games 2012] - gry przygodowej, w której podstawą doświadczenia jest fabuła. Zgadzam się z intuicją, że zjawisko immersji i zjawisko zaangażowania w formalny system gry są sobie przeciwstawne, jednak nie wyklucza to użycia obu struktur jednocześnie. Uważam, że mechaniki i reguły gry mogą wspierać zarówno jeden jak i drugi typ zaangażowania, a jedynym sposobem na wspieranie immersji nie jest minimalizacja zasad gry, ale raczej ich odpowiednie zaprojektowanie. Na końcu artykułu wymieniam cechy projektów, które koncentrują się na jednym lub drugim podejściu do rozgrywki. 
Już w tytule swojej książki - Half-Real - Video Games between Real Rules and Fictional Worlds [2005] Jesper Juul dzieli grę na dwa zasadnicze elementy: zasady i świat gry. W tym spojrzeniu granie w gry komputerowe jest zarazem uczestnictwem w fikcyjnej fabule jeżeli taka występuje $\mathrm{w}$ danym tytule, jak i interakcją z realnie istniejącym zestawem reguł modelujących rozgrywkę. W przeciwieństwie do radykalnych poglądów przedstawianych w okresie sporu ludologii z narratologią, Juul przyznaje, że element narracyjny nie tylko w dużym stopniu charakteryzuje grę, ale jest też ściśle związany z mechaniką. Mimo to, autor w swoich interpretacjach wyraźnie rozdziela narrację i zasady, a przede wszystkim wyznacza im różnorodne role. Zgadzam się $\mathrm{z}$ taką kategoryzacją, jednak w poniższym artykule koncentruję się na zasadach, które wspierają zaangażowanie w fabułę lub w formalne zasady gry. Bliższe perspektywie prezentowanej w tym tekście są wcześniejsze stanowiska takich autorów jak Alexander R. Galloway czy Janet Murray. Murray interpretuje całość gry jako doświadczenie narracyjne, nie przez wzgląd na budowę tego medium, ale raczej z powodu powszechnej ludzkiej skłonności do nadawania formy fabularnej wszelakim wydarzeniom. W swoim tekście Od gry-opowiadania do cyberdramy [Murray 2010] autorka pisze: „Co jest ważniejsze, opowiadanie czy gra? Dla mnie zawsze opowiadanie, bo przedstawianie historii to podstawowa ludzka aktywność, którą podejmujemy w każdym środku wyrazu - od oralno-schematycznych po cyfrowe multimedia” [Murray 2010, 64]. Natomiast Galloway wychodzi od zaprojektowanego przez twórców gry zestawu wyzwań którym użytkownik musi sprostać. W jego perspektywie „Grać w grę to tyle, co grać w kod gry. Wygrać to tyle, co poznać system. A więc by zinterpretować grę należy zinterpretować jej algorytm" [Galloway 2006, 90-91]. Przedstawione perspektywy badawcze przypominają zestaw opinii wygłaszany w ramach wspominanego sporu ludologii z narratologią. Za centrum tej polemiki można uznać pytanie czy esencją gry jest doświadczenie narracyjne czy nauka systemu mechanik gry. Co za tym idzie, czy znaczeniotwórcza aktywność odbiorcy koncentruje się na interpretacji fabularnej gry, czy na interpretacji doświadczenia rozgrywki tworzonych przez system reguł?

Immersja

Podejmując temat zaangażowania gracza należy się odnieść do pewnego terminu wywodzącego się z literaturoznawstwa. Celem niniejszego artykułu nie jest rewalidacja tego pojęcia - przytaczam, więc jedynie najważniejsze koncepcje dotyczące immersji. Należy zwrócić uwagę, że omawiany termin posiada również rozbudowaną teorię $\mathrm{w}$ dziedzienie psychologii, lecz nie jest on tożsamy z jego odpowiednikiem w litera- 
turoznawstwie i naukach o mediach. Jest to silne zaangażowanie w tekst medialny, podczas którego odbiorca odsuwa od siebie świadomość zapośredniczenia tekstu. W ten sposób przedstawia immersję Janet Murray, według niej „pobudzająca narracja [podkreślenie - M.P.] w jakimkolwiek medium może być doświadczana jako wirtualna rzeczywistość ponieważ nasz umysł jest zaprogramowany tak, by dostroić się do fabuły z taką intensywnością, że znika świat poza nami”1 [Murray 1998, 98-99]. Immersja oznacza u niej zanurzenie w innej rzeczywistości. Inną badaczką stosującą pojęcie immersji do gier jest Marie-Laure Ryan, która łączy ten typ zaangażowania z metaforą transportacji, bycia pochłoniętym przez tekst, światem możliwym i zawieszeniem niewiary [por. Ryan 2001, 89-114]. W podobnym ujęciu pisze łódzka badaczka Katarzyna Prajzner, w książce Tekst jako świat i gra. Modele narracyjności $w$ kulturze współczesnej, w której odbiór tekstu jako świata i związane z tym pojęcie immersji przeciwstawia recepcji tekstu jako gry i pojęciu interaktywności [Prajzner 2009, 55]. W tych modelach, silnie zakorzenionych w literaturoznawstwie, by osiągnąć immersję „można posłużyć się dowolną techologią lub (jak wolą niektórzy) dowolnym medium, zdolnym do wygenerowania reprezentacji świata dzięki dostępnym sobie środkom zarówno wizualnym jak i językowym” [Prajzner 2009, 23]. W kontraście do tych prezentacji terminu „immersja” stoją nowsze koncepcje badaczy związanych z badaniem gier. W tekście Cynizm gracza komputerowego Graeme Kirkpatrick [2010] omawia i opisuje rolę mechaniki i narracji w doświadczaniu gry. Jego „cyniczny” użytkownik to taki, który zawiesza niewiarę oraz świadomość tego, że włączając grę będzie wchodził w interakcje $\mathrm{z}$ maszyną. $\mathrm{Z}$ jednej strony akceptuje fikcyjne znaczenia świata gry, ale w tym samym czasie skupia się także na zdobywaniu kompetencji technologicznych i nauce systemu. W przeciwieństwie do poprzednich autorów Kirkpatrick mówi o równoległym zaangażowaniu gracza w fabułę i mechanikę. Zamiast opozycji, przedstawia on współzależność tych postaw. Laura Ermi i Frans Mäyrä w swoim modelu SCI rozszerzają ten termin [Ermi i Mäyrä 2005, 7-8]. Najbliższa znaczeniowo poprzednim koncepcjom jest immersja wyobrażeniowa - „doświadczenie gry w którym jesteśmy zaabsorbowani fabułą i światem lub zaczynamy wczuwać się lub identyfikować z postacią w grze" [tamże, 8]. Drugim typem immersji jest efekt zanurzenia w tekście (immersja sensoryczna) związany z audiowizualną warstwą gry i użyciem rozwiniętych technologii reprezentacji takich jak fotorealistyczna grafika, duży ekran czy system dźwięku przestrzennego. Model SCI zawiera również zaangażowanie w wyzwanie jakim jest gra (challenge-based immersion). Inny badacz gier,

1 Cytaty z obcojęzycznych źródeł, jeśli nie zaznaczono inaczej, podaję we własnym przekładzie. 
który poświęcił całą książkę zagadnieniu immersji w grach, Gordon Calleja, posługując się pojęciem ram Ervinga Goffmana, wyszczególnia sześć ram zaangażowania gracza. Są nimi:

- $\quad$ zaangażowanie taktyczne związane z planowaniem i podejmowaniem decyzji w trakcie rozgrywki,

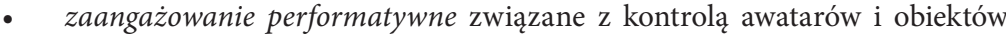
w grze, wykonywaniem czynności zaplanowanych w zaangażowaniu taktycznym,

- zaangażowanie affektywne związane $\mathrm{z}$ odczuwaniem przez gracza emocji i afektywnym przeżywaniem specyficznych doświadczeń prezentowanych przez grę,

- $\quad$ zanagażowanie wspólnotowe związane z komunikacją i poczuciem relacji gracza ze wszystkimi innymi agentami w grze,

- $\quad$ zaangażowanie narracyjne związane $\mathrm{z}$ dwoma typami narracji - zaprojektowaną narracją, taką jak fabuła gry czy historia świata fikcyjnego gry oraz osobistą narracją czyli historią działań gracza w tekście,

- zaangażowanie przestrzenne związane ze „zlokalizowaniem siebie w szerszej przestrzeni gry niż to co widać na ekranie" [Calleja 2007, 88]

Tak szerokie ujęcie terminu immersja, choć precyzyjne, wydaje mi się zbyt odległe od jego literaturoznawczego rodowodu, a w związku z tym immersja staje się synonimem słowa zaangażowanie. Moim zdaniem termin „immersja” jako posiadający swoją historię w odniesieniu do nieinteraktywnych mediów narracyjnych, powinien zachować swój nierozerwalny związek z narracją i fikcyjnym światem. Podobny wniosek, choć inaczej uargumentowany, podaje na końcu swojego artykułu Calleja proponując zamianę metafory immersji na inkorporację: „subiektywne doświadczenie zamieszkiwania wirtualnego środowiska wzmożone przez możliwość znaczącego działania w owym środowisku, będąc zarówno obecnym dla innych" [tamże, 89-90]. Z tego powodu w artykule posługuję się immersją w znaczeniu użytym przez Murray, Ryan i Prajzner.

\section{Zaangażowanie w narrację}

Wbrew temu co postulowali ludologowie, fabuły są niezwykle ważne dla gier komputerowych. Wystarczy spojrzeć na jakikolwiek konwent poświęcony kulturze gier: cosplayerzy przebrani za swoje ulubione postaci, fani rozmawiający na temat swoich 
wyborów fabularnych oraz pisarze amatorzy tworzący apokryficzne historie bohaterów gier. Fandom jest ściśle związany z fabułą. Do opisania tego typu przyjemności i zaangażowania w gry używam opisanego terminu immersji.

\section{Zaangażowanie w system formalny gry}

Z drugiej strony, dla opisu zaangażowania w mechanikę nie powstał żaden specjalny termin w środowisku badaczy gier. Jednakże zarówno wśród graczy ${ }^{2}$, jak i projektantów gier, ta kategoria zjawisk jest rozpoznana i nazwana. Przykładowo twórca gier i autor wielu książek na temat ich projektowania - Ernest Adams, nazywa strategiczną immersją [Adams 2004], aktywność intelektualnego zaangażowania w zasady gry. Z kolei zachowanie wokół gry - graczy optymalizujących swoje postaci do Dungeons and Dragons [Arneson i Gygax 1974-2008], dopracowujących zestawy wyposażenia w World of Warcraft [Blizzard Entertainment 2004], czytających podręczniki do gry w szachy, jak i tych uczących się skomplikowanych kombinacji w Mortal Kombat [Midway Games 1992-2011] jest ważną częścią zaangażowania kognitywnego graczy hardcore’owych [patrz: Grabarczyk 2015]. Chociaż ich aktywność może wydawać się różna, łączy je konieczność pogłębiania swojej wiedzy na temat zasad rządzących grą i chęć optymalizacji swoich strategii rozgrywki. Z przedstawionych wcześniej koncepcji Ermi i Mäyry najbliższe byłoby zaangażowanie w wyzwanie gry, jednak w tym terminie nie zawarto chęci gracza do zrozumienia i nauki systemu rządzącego rozgrywką. Z drugiej strony rama zaangażowania taktycznego Gordona Callejo sugeruje kompetytywne nastawienie gracza i nie bierze pod uwagę chęci zrozumienia reguł gry dla samej przyjemności poznania jej działania. W związku z powyższym w niniejszej pracy będę posługiwał się sformułowaniem „zaangażowanie w system formalny gry”, choć przywołane konceptualizacje zaangażowania są bliskie mojemu podejściu.

\section{Struktura MDA}

Do opisu systemu formalnego użyłem struktury MDA (ang. Mechanics, Dynamics, Aestethics) [Hunicke i in. 2004] - narzędzia dla badaczy i projektantów gier, prezentowanego na warsztatach w ramach Game Developers Conference w San Jose w latach 2001-2004. Podstawą tego modelu analizy jest podział systemu gry na trzy elementy:

1) mechanics - rozumiane jako reguły gry,

2) dynamics - pętle interakcji między graczem a mechanikami,

2 W środowisku graczy pojawiają się takie pojęcia jak powergaming czy theorycrafting, ale są one związane z konkretnymi gatunkami i społecznościami graczy i w związku z tym nie byłyby funkcjonalnymi terminami w powyższym artykule. 
3) aestethics - rozumiane jako zestaw emocjonalnych odczuć jakie budzi w użytkowniku rozgrywka.

Użycie mechanik i dynamik pozwala na rozróżnienie pojedyńczych zaprojektowanych reguł interakcji (mechanik) od wynikających z nich w grze powtarzalnych pętli (dynamik). Tych terminów będę używał wedle przedstawionych tu definicji. Natomiast nazwa ostatniego z tych pojęć wydaje się nieintuicyjna, dlatego też będę zamiast niej używał określenia doznanie, by opisać to co autorzy koncepcji nazywali estetyką. Według autorów MDA aesthetics miałoby być zastępstwem nieprecyzyjnego słowa "fun” jakiego używają projektanci gier, by określić pożądaną przyjemność jaką gra wyzwala w odbiorcy, a która niekoniecznie musi być kolokwialnie rozumianą przyjemnością, jak na przykład w grach z gatunku horroru [patrz: Koster 2005]. W pełnej analizie systemu formalnego gry musiałoby się również znaleźć miejsce dla warstwy fabularno-estetycznej jednakże wykracza to poza zakres tego artykułu.

\section{Analiza gier}

Do analizy wybrałem dwie gry: Angry Birds oraz The Walking Dead. Różnią się one pod wieloma względami, ale łączy je pewna oszczędność w ilości wykorzystanych systemów mechanicznych. W pierwszym tytule możemy jedynie wyrzucać ptaki z procy, w drugim natomiast przez większość czasu oglądamy sceny QTE ${ }^{3}$. Podstawową rozbieżnością między nimi jest sposób oraz przyjemności wynikające $\mathrm{z}$ ich konsumpcji. Angry Birds to typowa gra casualowa, na platformy mobilne, przeznaczona do krótkich, częstych rozgrywek i powtórnego grania. The Walking Dead była wydawana w odcinkach, zaprojektowana tak by każdy z nich można było ukończyć w ramach jednej, góra dwóch sesji. Strzelanie pociskami w grze firmy Rovio bazuje na seryjności doznawania na przemian: napięcia związanego z wyzwaniem i ulgi wynikającej z satysfakcji, płynących z rozwiązania łamigłówki; tymczasem prowadzenie swojego bohatera w postapokaliptycznym świecie odpowiada raczej przyjemności oglądania trzymającego w napięciu serialu, z którego bohaterami widz zżywa się i identyfikuje. Mimo tych różnic obie gry czynią z zaprojektowanych mechanik bardzo istotny składnik produkcji warunkujący doświadczenie rozgrywki.

3 QTE (ang. Quick Time Event) - mechanika umieszczana najczęściej w przerywnikach filmowych, opiera się na szybkim naciskaniu przycisków zaraz po tym jak komendy pojawią się na ekranie. Służy dodaniu aspektu interaktywnego, tradycyjnie nieinteraktywnym przerywnikom filmowym. 


\section{Angry Birds}

Angry Birds to jedna z najbardziej znanych gier na platformy mobilne. To również tytuł, który jednoznacznie kojarzy się z Casualową Rewolucją - dynamicznym wzrostem rynku gier tworzonych dla graczy niedzielnych w pierwszej dekadzie XXI wieku. Przebój na platformy mobilne firmy Rovio to bardzo prosta gra opowiadająca historię o grupie ptaków próbujących odebrać swoje jajka skradzione przez świnie. W tej kreskówkowej oprawie gracz ma za zadanie strzelać różnego rodzaju ptakami z procy, by zniszczyć konstrukcje, w których schroniły się świnie.

Ta prosta gra posiada niewiele zasad i zaledwie jedną podstawową mechanikę. Użytkownik celuje i wyrzuca zwierzęta w kierunku budowli; może on kontrolować nachylenie oraz siłę strzału. Rozrywka kierowana jest zasadami fizyki układu (strzał z procy, grawitacja, fizyka elementów konstrukcyjnych fortów). Na każdym poziomie dostępna jest ograniczona ilość ptaków-pocisków, służących do zniszczenia coraz to nowych budynków.

Podstawową dynamiką gry (pętlą interakcji gra - gracz) jaką aktywuje gracz jest: użycie procy z ptakiem - skorygowanie strzału (na podstawie dokonanych zniszczeń, zaznaczonej trajektorii oraz nachylenia strzału) - ponowny strzał z procy. To interakcja, która stanowi całość gry Angry Birds. Pozostałe elementy gry to dodatki narracyjne i estetyczne lub rozwinięcia opisanej dynamiki.

Rozwój gry z poziomu na poziom opiera się na strukturze danego budynku, nowych rodzajach bardziej wytrzymałych wrogów, a także kolejnych typach ptaków. Te trzy elementy urozmaicają naprzemiennie podstawową dynamikę wprowadzając nowe wyzwania i trochę inne możliwości. Co kilka poziomów pojawia się również krótka animacja przedstawiająca dalszy ciąg historii zmagań ptaków ze świniami. Choć jest to niewielka ilość narracji, umieszcza rozgrywkę w jakimś kontekście wydarzeń oraz w uniwersum całej serii Angry Birds.

Przyjemności tej gry płyną głównie z pokonywania wyzwań, ulegania ustrukturyzowanej aktywności jaką jest spędzanie czasu w grze, a także po części eksploracji możliwości zaprojektowanych w kolejnych poziomach. Odczuwanie satysfkacji z rozwiązywania kolejnych problemów jakimi są poziomy jest podstawą Angry Birds, jak również wielu innych gier casualowych. Przejście każdego etapu dostarcza użytkownikowi satysfakcji, proporcjonalnej do wysiłku jaki włożył w rozwiązanie łamigłówki. Ponieważ poziomy są małe, a ich wyzwania niezbyt skomplikowane, gracz otrzymuje dawkę satysfakcji często, ale w niewielkich porcjach. To powoduje, że łatwo dać się wciągnąć w niekończącą się sesję rozgrywki, próbując przejść „jeszcze jeden poziom”. Jasno skonstruowane zasady i cel, często powtarzalne sprzężenie zwrotne, stałe do- 
starczanie zadań o rosnącej trudności sprawiają, że niełatwo oderwać się od gier casualowych. Zaangażowanie przez strukturę formalną rozgrywki (dynamiki) oraz budowę gry (budowa poziomów) w opisany sposób możemy określić pojęciem flow ${ }^{4}$.

\section{The Walking Dead}

The Walking Dead to gra przygodowa wydawana w formie odcinkowej na podstawie komiksu o grupie ludzi próbujących przetrwać w świecie zarażonym żywymi trupami. Zadaniem użytkownika jest kierowanie głównym bohaterem, wykonywanie prostych czynności, wybieranie linii dialogowych oraz rozwiązywanie krótkich zadań, pomiędzy którymi znajdują się duże fragmenty przerywników filmowych. Po premierze The Walking Dead jednym z zarzutów krytyki była niewielka ilość typowych dla gatunku gier przygodowych wyzwań oraz brak konsekwencji wyborów fabularnych.

Dostępne mechaniki są w pełni uzależnione od sceny: znajdują się wśród nich mechaniki wyboru linii dialogowych, mechaniki związane z ruchem, mechaniki zbierania i używania przedmiotów, a także występujące jednorazowo w scenach akcji - mechaniki wykonywania szczególnych działań (w formie QTE). Wymieniony zestaw to standardowe składniki klasycznych gier przygodowych jednakże sposób wykorzystania tych zasad w The Walking Dead czynią tę grę wyjątkową.

Podstawową dynamiką tradycyjnych przygodówek takich jak The Secret of Monkey Island [Lucasfilms Games 1990] czy The Longest Journey: Najdtuższa podróż [Funcom 1999] jest znajdowanie przedmiotów oraz szukanie możliwości ich zastosowania w różnych lokacjach. W The Walking Dead natomiast jest to raczej oglądanie przerywników filmowych i wykonywanie poleceń albo eksplorowanie przestrzeni w poszukiwaniu elementów interaktywnych. We wcześniejszych tytułach reprezentujących ten gatunek użytkownik miał rozwiązywać łamigłówki i odkrywać nowe obszary, aby w nagrodę posunąć fabułę naprzód. Tymczasem „serialowi” studia Telltale znacznie bliżej do interaktywnych filmów produkcji Quantic Dream np.: Fahrenheita [2005]. W The Walking Dead znajdziemy sceny statyczne - kiedy świat stoi w miejscu i czeka aż protagonista wykona jakieś zadanie oraz sceny dynamiczne - przerywniki filmowe podczas których czas płynie niezależnie od gracza, a on musi reagować na toczącą się akcję. Ten drugi typ sekwencji przeważa w produkcji o żywych trupach i nadaje jej wyjątkowego charakteru.

4 Flow - w psychologii termin ten tłumaczony jest jako „przepływ”, jednakże w odniesieniu do gier nie jest on tożsamy z terminem autorstwa Mihály Csíkszentmihály, używam określenia angielskiego [por. Koster 2013; Csíkszentmihályi 2010]. 
Rozwój gry i motywacja gracza do dalszej rozgrywki opiera się na czysto fabularnych aspektach. Rozwiązywanie kolejnych wyzwań, wykonywanie następujących po sobie zadań powoduje, że historia toczy się dalej, a użytkownik może w niej uczestniczyć.

Moim zdaniem doznania w The Walking Dead są tego samego rodzaju co doznania płynące z odbioru medium literackiego czy filmowego, w którym utożsamiamy się emocjonalnie z bohaterem i opowiadaną historią. Doświadczenie rozgrywki jedynie intensyfikuje ten rodzaj przeżyć, daje nam dostęp do współtworzenia fabuły, sprawia, że trudniej nam odrzucić motywacje, którymi kieruje się bohater. Na podstawie tej analizy projektu rozgrywki produkcji Telltale games stawiam hipotezę, że przyjemność wynikająca z obcowania z The Walking Dead, jest bliźniaczo podobna do tej jaka towarzyszy czytaniu powieści przygodowej.

\section{Podsumowanie analiz doznań i mechanik}

Projekt mechanik Angry Birds zachęca do zaangażowania w system formalny gier, tymczasem w The Walking Dead mechaniki są związane bezpośrednio z fabułą. Bez zrozumienia, przetestowania i nauki zasad grawitacji, strzału z procy, charakterystyki poszczególnych ptaków i zachowań różnych materiałów budulcowych, czerpanie przyjemności z produkcji Rovio Entertainment byłoby utrudnione. Natomiast w świecie zdominowanym przez żywe trupy, mechaniki kontroli protagonisty wzmacniają identyfikację odbiorcy z fikcyjnymi wydarzeniami, wzmagają napięcie, świadomość wpływu na bieg zdarzeń oraz poczucie odpowiedzialności. Pierwsza z przywoływanych gier konstruuje swoje zasady w celu wywołania przyjemności związanej z nauką nowych umiejętności i wygrywaniem, tymczasem druga wzmacnia przekaz emocjonalny płynący z prezentowanej historii; mechaniki Walking Dead intensyfikują immersję, tymczasem mechaniki Angry Birds każą mu zaangażować się w system formalny gry.

\section{Cechy dwóch doznań}

Największe produkcje głównego nurtu zazwyczaj są zaprojektowane tak, aby zaangażować gracza zarówno w algorytm gry, jak i wywołać immersję. Nawet w grach bazujących na zaangażowaniu w system formalny gry jak Starcraft II: Wings of Liberty [Blizzard Entertainment 2011] pojawia się coraz więcej elementów fabularnych, a nawet wyborów zakończeń. Sztandarowym przykładem, który łączy obie przedstawione $\mathrm{w}$ artykule tendencje jest gatunek komputerowych gier fabularnych (cRPG). Tytuły takie jak Mass Effect [BioWare 2007-2012] czy Skyrim [Bethesda Game Studios 2011] 
posiadają rozbudowane systemy walki, które bez wątpienia stanowią rdzeń doświadczenia rozgrywki. Jednakże drugim podstawowym ich elementem są składniki narracyjne takie jak fabuła, dialogi czy historia świata. Jednakże The Walking Dead i Angry Birds oraz większość średnich rozmiarów gier koncentruje się jedynie na jednym z wymienionych typów zaangażowania. Odpowiednie zaprojektowanie mechanik najczęściej wspiera podstawowy tryb zaangażowania albo jest warunkiem jego zaistnienia. Poniżej wymieniam cechy systemów formalnych wspomagających immersję oraz tych skłaniających gracza do koncentracji na zasadach rozgrywki.

\section{Elementy angażujące w system formalny gry:}

Powtarzalność i konsekwencja mechanik - Każdy kolejny etap, poziom czy scena w grze jest oparta o te same powtarzane mechaniki podstawowe, które zawsze zachowują się tak samo (przeciwieństwem tego są mechaniki kontekstowe). Większość starożytnych gier planszowych takich jak pachisi czy tryktrak opiera się na ograniczonej ilości mechanik powtarzanych w każdej turze, na każdym etapie gry.

Losowość - Sceny w których uczestniczy gracz mają charakter losowy lub przynajmniej ilość możliwych kombinacji jest tak duża, że sekwencja ma za każdym razem inny przebieg. Przykładowo: walki w kampaniach serii Call of Duty [Infinity Ward 2003-2014] mają predefiniowane kluczowe miejsca na mapie oraz rozstawienie wrogów, jednakże wraz z rozwojem bitwy, w zależności od zachowań gracza, przybierze różne formy. Będzie to wynikiem zarówno losowych elementów (fizyki świata) jak i zaprogramowanych zachowań (trybów walki wroga).

Jawne zasady - Zasady rozgrywki i działania poszczególnych mechanik są dostępne wszystkim graczom i zostały jasno przedstawione. Podobnie jak w sporcie, reguły powinny być dla każdego klarowne oraz stosować się do wszystkich w ten sam sposób. Przykładowo, w Borderlands [Gearbox Software 2009-2014] każda broń ma opis działania, co oznacza, że nie posiada ona żadnych ukrytych zasad oraz, że na każdego wroga musi działać w ten sam sposób (w ramach przyjętych reguł). Wyjątek stanowią gry, w których zaangażowanie w system formalny rozgrywki łączy się z przyjemnością odkrywania zasad, jak w Binding of Isaac: Rebirth [Nicalis 2014]. W tym przypadku jawność rozumiem jako jasny sygnał jaki daje gra, gdy dana mechanika została uruchomiona.

Krótka pętla interakcji - Czas reakcji systemu mechaniczego gry na sygnał od gracza jest stosunkowo krótki, a informacje zwrotne zawsze dostępne dla użytkownika. W strzelankach takich jak Borderlands, podstawowa pętla interakcji wygląda następująco: gracz celuje, strzela, kula chybia lub trafia, występuje efekt graficzny 
trafienia bądź chybienia, gracz koryguje cel. Czas pomiędzy strzałem a efektem jest minimalny. Kontrprzykładem są ciężkie gry strategiczne z gatunku war games lub tradycyjne szachy: popełnione wybory w początkowym etapie gry poskutkują dopiero pod koniec rozgrywki. Co prawda, wprawny gracz już wcześniej może ocenić wartość danego posunięcia, a nawet ten mniej wprawny odczuje efekty swojego ruchu gdy straci jednostkę lub figurę. Krótka pętla interakcji zachęca do nauki systemu mechanicznego gry w trakcie grania, długie pętle interakcji takie jak w szachach wymagają analizy rozgrywki i nauki po zakończeniu partii.

\section{Elementy gry angażujące w narrację:}

Niepowtarzalność wyzwań - Każda scena, etap, poziom są wyjątkowe pod względem swojej budowy; mogą używać podobnych mechanik, ale konkretne działania są inne. Przykładem mogą być sceny dialogowe w serii Baldur's Gate [BioWare 1998-2001]: za każdym razem wypowiedzi rozmówców przedstawione są w ten sam sposób, gracz stosuje te same mechaniki by wybrać opcję dialogową, jednak zawsze jest to odmienna sytuacja w której zestaw wypowiedzi jest inny, ich ilość może być różna, a same zasady rządzące konwersacją są zależą od intencji rozmówców.

Niska trudność - Wyzwania przedstawione w grze nie mogą być na tyle trudne, by odciągać uwagę od elementów fabularnych. Szczególnie w grach akcji, strzelankach lub cRPG walka bywa na tyle skomplikowana, że czasami zniechęca początkującego gracza lub sprawia, że będzie on musiał poświęcić nieproporcjonalnie więcej czasu na naukę systemu niż na przeżywanie opowieści. Jest to problem na tyle popularny, że zainteresował deweloperów z BioWare, którzy w Mass Effect 3 [2012] umieścili „tryb fabuły”, koncentrujący się na elementach narracyjnych, ekstremalnie upraszczający potyczki [Francis 2012].

Wyraźne konsekwencje wyborów - Wybory fabularne są często używaną mechaniką w grach skupiających się na narracji, dlatego wymagają szczególnej uwagi. Po pierwsze, podjęte decyzje muszą mieć wyraźne konsekwencje w świecie gry, by gracz mógł poczuć, że jest bohaterem fabuły, a nie drugorzędną bierną postacią. Drugą niezwykle ważną kwestią przy projektowaniu wyborów jest ich związek z konsekwencjami mechanicznymi gry. Jeżeli chcemy, by gracz podjął decyzję na podstawie znaczenia fabularnego, konsekwencje wyboru nie mogą być łatwe do przekalkulowania na wartości mechaniczne.

Brak możliwości porażki - Zasada, by w grze nie było możliwości przegranej wydaje się kontrowersyjna, ale moim zdaniem takie rozwiązania jak jasno określona ścieżka fabularna skutkująca jednoznacznie porażką lub zwycięstwem działają prze- 
ciw immersji ponieważ niszczą wiarygodność świata. Fikcyjna rzeczywistość traci swoją autentyczność w momencie gdy gra pokazuje nam, że jest de facto tylko jedną opowieścią, a nie światem w którym różne opowieści są możliwe. Dlatego w długich grach fabularnych głównego nurtu możliwe zakończenia przedstawiają lustrzane odbicia tego samego scenariusza. Znanym przypadkiem gdy warianty finału gry prawie niczym się od siebie nie różniły, było zamknięcie sagi Mass Effect, które w bardzo małym stopniu odpowiadało wyborom użytkowników. Jednakże pisząc „brak możliwości porażki” niekoniecznie mam na myśli dopuszczanie jedynie scenariuszy gdzie protagonista wygrywa, ale takie prowadzenie fabuły, by użytkownik nie poczuł, że nie wypełnił jakiejś części gry, nie doprowadził opowieści do końca.

\section{Podsumowanie}

Kulturze gier komputerowych od dawna, towarzyszy napięcie między elementami narracyjnymi odziedziczonymi po literaturze, a specyficznymi dla nich elementami mechanicznymi. Choć pierwsze gry bazowały na zaangażowaniu w system formalny gier, już wczesne produkcje jak Adventure [Crowther i Woods 1977] sprawiły, że fabuła znalazła się w kręgu zainteresowania twórców gier. Gatunek tekstowych gier przygodowych wprowadził na szeroką skalę przyjemności narracyjne do elektronicznej rozgrywki. Współczesne rozbudowane gry cRPG kontynuują tę tradycję, jednakże system formalny zawsze był w nich co najmniej równie ważny - spadek po niecyfrowych grach bitewnych. Powyższy artykuł opisywał dwojakie zaangażowanie gracza, przez pryzmat zaprojektowanego systemu formalnego. Był to jednak zaledwie przyczynek do głębszej analizy tej problematyki; w tym celu należałoby spojrzeć na zagadnienie $z$ drugiej strony - z perspektywy nauki badającej użytkownika, a nie tekst gry - psychologii. Kolejnym krokiem powinien być również artykuł poświęcony jednej dużej grze posiadającej zarówno systemy immersyjne jak i systemy angażujące w reguły gry. Przyjrzenie się typowej grze AAA z takich serii jak Mass Effect, Call of Duty czy Batman Arkham [Rocksteady Studios 2009-2011] powinno zweryfikować listę cech przynależących do każdego z dwóch typów zaangażowania.

\section{Bibliografia}

Adams, Ernest. 2004. The Designer's Notebook: Postmodernism and 3 Types of Immersion, Gamasutra, http://www.gamasutra.com/view/feature/130531/the_designers_notebook_.php 
Calleja, Gordon. 2007. Revising Immersion: A Conceptual Model for the Analysis of Digital Game Involvement. Proceedings of the 2007 DiGRA International Conference: Situated Play.

Calleja, Gordon. 2011. In-game from immersion to incorporation. Cambridge, Mass: MIT Press.

Csíkszentmihályi, Mihály, 2005, Przepływ: jak poprawić jakość życia: psychologia optymalnego doświadczenia, Taszów: Biblioteka Moderatora.

Ermi, Laura, Frans, Mäyrä. 2010. Fundamental components of the gameplay experience: analysing immersion. w: Suzanne de Castell and Jennifer Jenson (red.), Proceedings of Chancing Views - Worlds in Play. Digital Games Research Association's Second International Conference. Vancouver: DiGRA and Simon Fraser University.

Francis, Tom. 2012, Mass Effect 3 Narrative Mode and Action Mode Explained, PC Gamer, http://www.pcgamer.com/mass-effect-3-narrative-mode-and-action-modeexplained/.

Galloway, Alexander R. 2006, Gaming, Essays on Algorithmic Culture, Minneapolis: Minneapolis University Press.

Grabarczyk, Paweł. 2015, O opozycji hardcore/casual, „Homo Ludens” 1(7), [w druku] Hunicke, Robin, LeBlanc, Mark, Zubek, Robert. 2004, MDA: A Formal Approach to Game Design and Game Research, http://www.cs.northwestern.edu/ hunicke/ MDA.pdf.

Juul, Jesper. 2005, Half-Real - Video Games between Real Rules and Fictional Worlds, Cambridge: MIT Press.

Koster, Raph. 2005. A Theory Of Fun In Game Design. Scottsdale: Paraglyph Press.

Murray, Janet. 1998, Hamlet on the Holodeck: The Future of Narrative in Cyberspace, Cambridge: MIT Press.

Murray, Janet. 2010, Od gry-opowiadania do cyberdramy, przeł. M. Filiciak, w: Filiciak Mirosław (red.) Światy z pikseli. Antologia studiów nad grami komputerowymi, Warszawa: Wydawnictwo SWPS Academica.

Prajzner, Katarzyna. 2009. Tekst jako świat i gra: modele narracyjności w kulturze współczesnej. Łódź: Wyd. Uniwersytetu Łódzkiego.

Ryan, Marie-Laure. 2001. Narrative as virtual reality immersion and interactivity in literature and electronic media. Baltimore, Md: Johns Hopkins University Press. 
Bethesda Game Studios, 2011, The Elder Scrolls V: Skyrim [PC] USA, Bethesda Softworks.

BioWare, 1998-2001, Baldur's Gate [PC], USA, Black Isle Studios, Interplay.

BioWare, 2007-2012, Mass Effect [PC], USA, Microsoft Studios, Electronic Arts.

Blizzard Entertainment, 2004, World of Warcraft [PC] USA, Activision Blizzard.

Blizzard Entertainment, 2011, Starcraft II: Wings of Liberty [PC] USA, Blizzard Entertainment.

Crowther William and Woods Don, 1977, Collosal Cave Adventure [PDP-10] USA.

Dave Arneson, Gary Gygax, 1974-2008, Dungeons and Dragons, USA, Tactical Studies Rules, Wizards of the Coast.

David Cage, Quantic Dream, 2005, Fahrenheit, [PC] PL, Atari.

Gearbox Software, 2009-2014, Borderlands [Xbox 360], USA, 2K Games.

Infinity Ward, 2003-2014, Call of Duty [PC], USA, Activision.

Lucasfilms Games, 1990, Secret of Monkey Island [PC], USA, Lucasfilms Games.

Midway Games, 1992-2011, Mortal Kombat [Arcade, PC, Xbox 360], USA, Acclaim Entertainment, GTInteractive.

Nicalis, 2014, Binding of Isaac: Rebirth [PC] USA, Nicalis.

Ragnar Tørnquist, Funcom, 1999 The Longest Journey: Najdłuższa podróż [PC] PL, CD Projekt .

Rocksteady Studios, 2009-2011, Batman Arkham [PC], USA Warner Bros Interactive, Eidos Interactive.

Rovio Entertainment, 2009, Angry Birds [iOS], USA, Chillingo.

Telltale Games, 2012-2014, The Walking Dead [PC], USA, Telltale Games.

\section{Summary}

Rules versus immersion: engagement in game's narrative and engagement in formal system of the game

Rules and narratives in video games had a complicated relationship for many years. In game studies this conflict became evident in ludology versus narratology debate, in video game culture critics and players talk about ludo-narrative dissonance. Both of those phenomena express the popular belief that rules and story in videogames oppose each other, that strategic or tactical engagement and narrative immersion can- 
not coexist in one game. The following article confronts the problem of, supposedly, opposing types of engagement. To understand different aspects of engagement several concepts of immersion are recalled, beginning with those rooted in literary studies by Janet H. Murray, Marie-Laure Ryan and Katarzyna Prajzner, through game specific concept of Laura Ermi and Frans Mäyrä to post-immersion concepts of Gordon Calleja. In the next section of the paper two analyses of specific types of engagement are presented: game formal system engagement in Angry Birds [Rovio Entertainment, 2009] and narrative immersion in The Walking Dead series [Telltale Games, 2012]. The article concludes with a list of mechanical features of a video game that facilitates either engagement in formal system of the game or game's narrative.

Keywords: rules in video games, immersion, engagement, MDA

mgr Marcin Petrowicz - doktorant w Instytucie Sztuk Audiowizualnych Uniwersytetu Jagiellońskiego, przewodniczący krakowskiego Koła Polskiego Towarzystwa Badania Gier, naukowo zajmuje się grami - nie tylko komputerowymi, przede wszystkim w zakresie badania dynamik i mechanik. 